\title{
Turbulent Flow Behavior of Mixing Process Inside a Pharmaceutical Stirred Tank
}

\author{
V. Sharan, D. Bhuvaneshwar, R. Harish
}

\begin{abstract}
As mixing is an essential operation in many engineering fields a mixing system is designed using agitated vessels in which it is difficult to obtain accurate information on induced turbulence by the impeller where CFD can provide detailed understanding of such systems. Here the impeller is designed and tested in both single phase \&multiphase. Here specifically incompressible flow is used and Multiple reference frame is used to model the motion of the impeller zone. Hence, we study the flow characteristics by comparing the velocity and temperature contour of three different rotating speed of the impeller and predict the percentage increase and decrease for varying boundary conditions.
\end{abstract}

Keywords: Mixing tank, Moving Reference Frame, Large Eddy Simulation, Turbulence Flow, Computational fluid dynamics

\section{INTRODUCTION}

Mixing is an essential operation in many engineering fields. It has central significance in food processing, pharmaceutical production, chemical engineering, biotechnology, paint manufacturing, water purification among countless other applications. The mixing tank place a vital role in these applications for producing a homogenous mixing operation. Rahimi and Parvareh [1] numerically investigated the experimental and CFD investigation on mixing by a jet in a semi-industrial stirred tank in this paper the mixing curves in a semi-industrial tank equipped with a side entry jet mixer is analyzed using CFD by validating experiments. The homogeneity of the theoretical mixing curves was measured by a photometer. Here the RNG $\mathrm{k}-\varepsilon$ model is used which shows convincing results compared with the experimental results.

Naeeni and Pakzad [2] performed experiments in a droplet size distribution and mixing hydrodynamics in a liquid-liquid stirred tank by CFD modelling they absorbed that in many industries mixing tank plays a leading role in liquid dispersion, in which simulation of mixing of water in

Revised Manuscript Received on February 05, 2020.

* Correspondence Author

V. Sharan, Postgraduate Student, M.Tech (CAD/CAM), School of Mechanical Engineering, Vellore Institute of Technology, Chennai, Tamilnadu, India.

D. Bhuvaneshwar, Postgraduate Student, M.Tech (CAD/CAM), School of Mechanical Engineering, Vellore Institute of Technology, Chennai, Tamilnadu, India.

R. Harish*, Assistant Professor, Thermal and Automotive Research Group, School of Mechanical Engineering, Vellore Institute of Technology, Chennai, Tamilnadu, India. E-mail: harish.r@vit.ac.in

(C) The Authors. Published by Blue Eyes Intelligence Engineering and Sciences Publication (BEIESP). This is an open access article under the CC BY-NC-ND license (http://creativecommons.org/licenses/by-nc-nd/4.0/) crude oils in a mixing tank is equipped with Rushton turbine. A Eulerian multiphase model and standard $k-\varepsilon$ turbulence model are executed to simulate the flow field inside the tank. Here the computational fluid dynamics (CFD) is coupled with population balance model (PBM) which is used to calculate the gas bubble size distribution.

Meroney and Colorado [3] performed numerical experiments in a CFD simulation of mechanical draft tube mixing in anaerobic digester tanks they used to find the mixing characteristics of four different circular anaerobic digester tank simulation is done by Computational fluid dynamics (CFD). The digester volume turnover time (DVTT), mixture diffusion time (MDT), and hydraulic retention time (HRT) is used to calculate the rate of mixing of step and tracers of slug injection. Toshihiro et al. [4] performed experiments in a CFD geometrical optimization to improve mixing performance of axial mixer to observe the performance of the axial static mixers produces high pressure drop characteristics and wide frequency range of input disturbance cannot be filtered whereas the static Time Difference Type Mixer (TDM)" is a new practical axial mixer that reduces the intermittent variation concentration of the mixture.

This TDM was modified to decrease the pressure drop and smoothen the outlet concentration profile. Rammohan et al. [5] numerically investigated a lagrangian description of flows in stirred tanks via computer-automated radioactive particle tracking in this study, the characterization of the flow in stirred tanks is implemented by computer automated radioactive particle tracking (CARPT).Most of the important flow in stirred tank have been captured by CARPT technique and this technique is also used to find out the dead and active zones in the tank. Taghavi and Zadghaffari et al. [6] performed an experimental and CFD investigation of power consumption in a dual Rushton turbine stirred tank to absorb the determination of power consumption in a mixing tank is a key variable in chemical and bioprocess engineering. Laboratory investigation has been carried out in the power consumption of six bladed Rushton turbine in a single phase as well as gas liquid phase. Comparison of result is made with the CFD simulation of the experimental setup. Using predicted data, empirical correlation has been derived to find out the power consumption and flow regime in stirred tank with dual impeller. Vicumn and Mazzotti [7] performed experiments on multi-scale modeling of a mixing precipitation process in a semi batch stirred tank for the mixing of barium sulphate precipitation in a semi batch stirred tank reactor is investigated. A multi scale nature of the process which relates the phenomena with interaction between mechanism of different scales. Hence the strength of the complex model is determined with the CFD results of various operating conditions. 


\section{DESIGN OF MIXING TANK}

A tank is designed with a shaft holding an impeller which is positioned concentric to the axis of the tank. The outline of the tank and dimensions of the components are shown:

Table 1. Dimensions of the tank

\begin{tabular}{l|l|l|}
\hline Parameter & Symbol & Value(mm) \\
\hline Tank diameter & $\mathrm{T}$ & 350 \\
\hline Tank height & $\mathrm{H}$ & 400 \\
\hline Impeller diameter & $\mathrm{D}=\mathrm{T} / 2$ & 170 \\
\hline Impeller blade height & $\mathrm{H}$ & 10 \\
\hline Impeller clearance & $\mathrm{C}=\mathrm{D} / 3$ & 75.5 \\
\hline
\end{tabular}

The diameter of $0.012 \mathrm{~m}$ impeller is been holding by the shaft which is concentric to the shaft to that of the axis of the tank. In this tank setup the impeller used here is known to be called as Rushton impeller which is mainly designed for creating high turbulence and it is also mainly used in gas dispersion application as well.

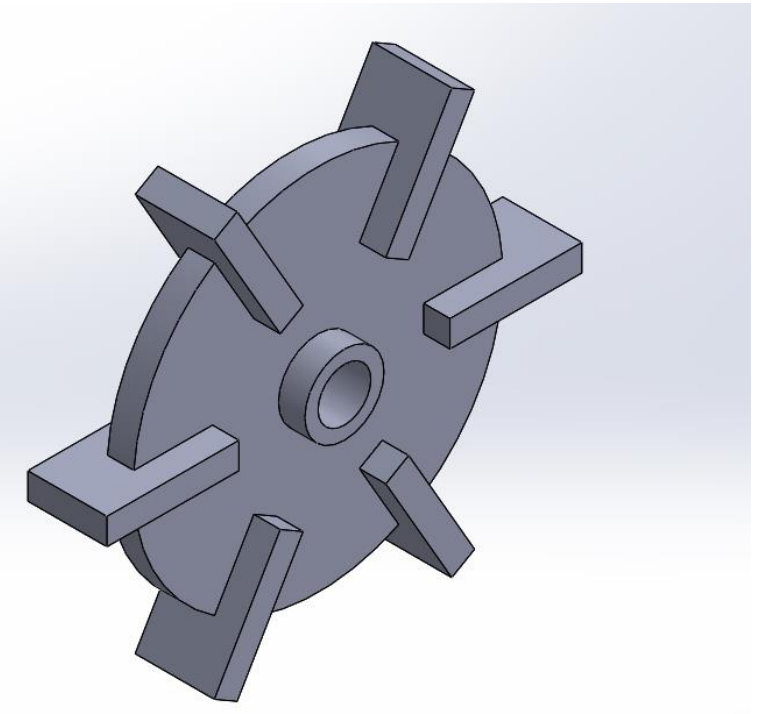

Figure 1 Schematic diagram of impeller

The figure 1 represent the schematic diagram of the Rushton impeller which has been used in mixing simulation.

\section{MODELING AND NUMERICAL METHOD}

Finite volume solver is used for performing numerical simulation, whereas the turbulence is induced where the problem is modeled as buoyancy. The Reynolds averaged Naiver-stokes (RANS) for getting the time average energy equation and temperature field. The k-e turbulence model is used for obtaining turbulence[8-13]. For the energy that includes surface and surface radiation, then the governing equation as to solve:

$$
\begin{gathered}
\frac{\partial \overline{u_{i}}}{\partial t}+\frac{\partial \overline{u_{i}}}{\partial x_{i}}=0 \\
\frac{\partial \overline{u_{i}}}{\partial t}+\overline{u_{j}} \frac{\partial \overline{u_{i}}}{\partial x_{j}}=-\frac{1}{\rho} \frac{\partial \bar{p}}{\partial \overline{x_{i}}}+\frac{\partial}{\partial x_{j}}\left[v \frac{\partial \overline{u_{i}}}{\partial x_{j}}-\overline{u_{i}^{\prime} u_{j}^{\prime}}\right]
\end{gathered}
$$

$$
\begin{aligned}
\frac{\partial \varepsilon}{\partial t}+\overline{u_{i}} \frac{\partial \varepsilon}{\partial x_{i}} & =\frac{\partial}{\partial x_{i}}\left[\frac{v_{t}}{\sigma_{k}} \frac{\partial \varepsilon}{\partial x_{i}}\right]+ \\
C_{1 \varepsilon} \frac{\varepsilon}{k} v_{t} & {\left[\frac{\partial \overline{u_{i}}}{\partial x_{j}}+\frac{\partial \overline{u_{j}}}{\partial x_{i}}\right] \frac{\partial \overline{u_{i}}}{\partial x_{j}}-C_{2 \varepsilon} \frac{\varepsilon^{2}}{k} }
\end{aligned}
$$

The general velocity and temperature is represented by ' $u$ ' and ' $e$ ' and the fields such as kinetic energy and dissipation fields and the density of fluid ' $\rho$ ' which plays a role The SIMPLE algorithm is used which tends to avoid the pressure velocity coupling. A small time step of $10^{-4}$ which is set by the convergence criterion.

\section{IV. MESHING AND PREPROCESSING}

The mixing tank and the impeller is been designed using Solid works 2019 software before being imported to ANSYS Fluent for Pre-processing and meshing. Using ANSYS workbench design modeler an interface is created between the contacting fluid region and boundary conditions were created. To discretize the domain into smaller region mesh is generated where by the computer numerical calculation the conservation of equations is approximated. The two main zones which are tank fluid region and the impeller region is to be meshed as it is modelled as a separate interacting fluid domain. As the mesh which is produced is very finite as the results will be as accurate for the computation to take place.

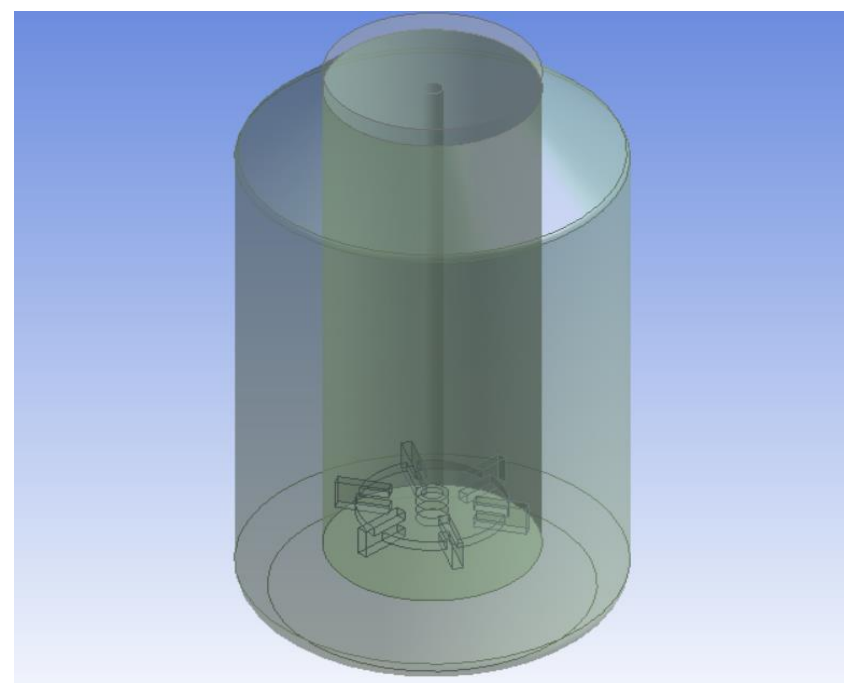

Figure2 Schematic geometry of the mixing tank

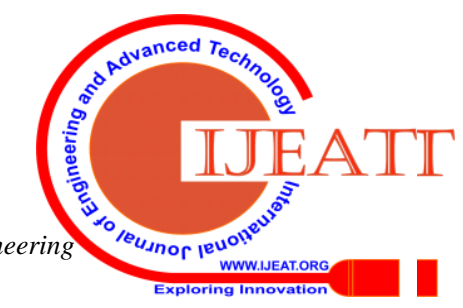




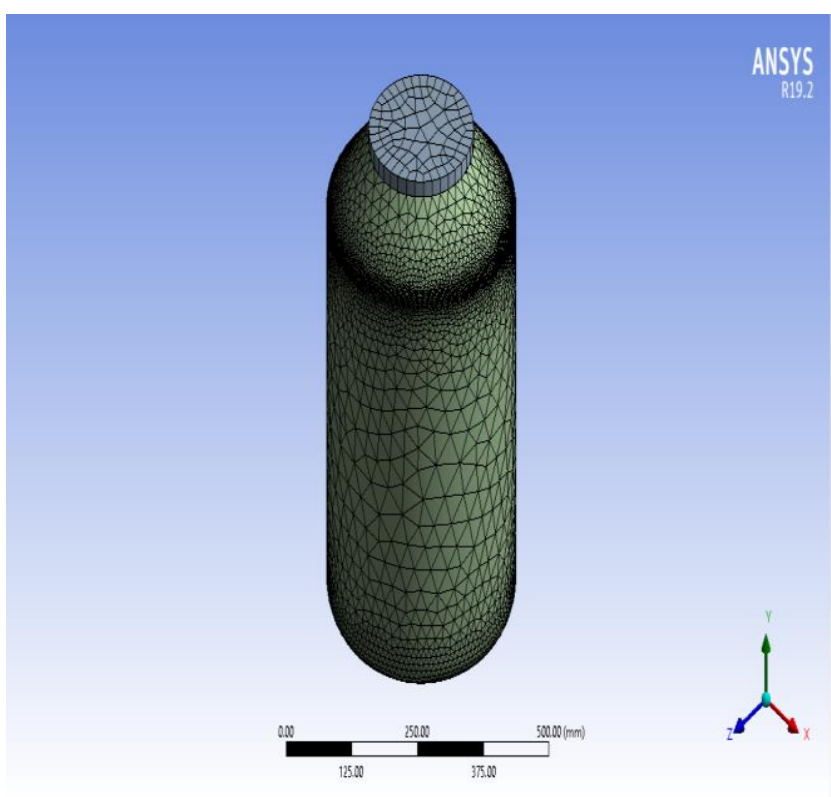

Figure3 Schematic diagram of Mesh

Figure 3 represent the general mesh view of the mixing tank. Here the mesh used is tetrahedron as it is been used to get a accurate discretization of uneven structure. The fluent solver is used to execute the simulation in which the absolute velocity and pressure based steady flow is executed with gravity acted along $y$-axis direction. The fluid region is set to viscous type, the k-e standard and no slip condition is used for the wall region.

The electrolyte material is taken as water with general properties of water of density $998.2 \mathrm{~kg} / \mathrm{m}^{3}$ and constant velocity of $0.001 \mathrm{~kg} / \mathrm{ms}$. The impeller fluid is entailed as the interface which consist of the impeller region and the fluid region.

Here (MRF) Multiple reference frame approach is used to model the movement of the impeller zone in tank region which computes both the stationary and moving frames. The impeller is subjected to rotated at three different case condition such as $4 \mathrm{rad} / \mathrm{sec}$, $8 \mathrm{rad} / \mathrm{sec}$, 12rad/sec along the $\mathrm{y}$-axis. Hybrid initialization technique is executed before running the calculation with an iteration of 10,000. The profiles such as velocity contour, pressure contour and streamline were generated using CFD-post process to exhibit the effect of impeller at each case condition.

\section{RESULTS AND DISCUSSION}

Figure 3 represent the general mesh view of the mixing tank. Here the mesh used is tetrahedron as it is been used to get a accurate discretization of uneven structure. As the mesh is very finite, the results will be as accurate as possible.

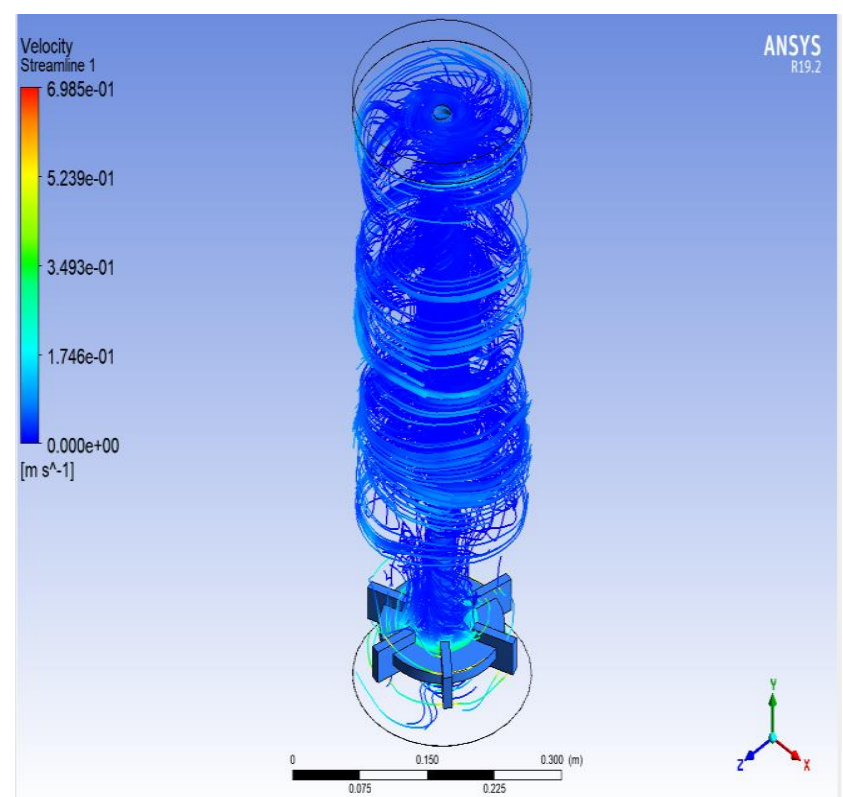

Figure 4. Streamline view of mixing process

The Figure 4 represents the streamline flow of the mixing process which is induced by the impeller. In this the impeller is rotated at three different speed conditions $4 \mathrm{rad} / \mathrm{sec}$, $8 \mathrm{rad} / \mathrm{sec}, 12 \mathrm{rad} / \mathrm{sec}$. Each of these speeds of rotational speed will tend to change the streamline pattern due to the change in velocity. The Figure 2.1 represents the insight view of the impeller in which the flow physics of vector can be viewed in detail. The velocity at the center is higher compared to that of the outer region which induces turbulence.

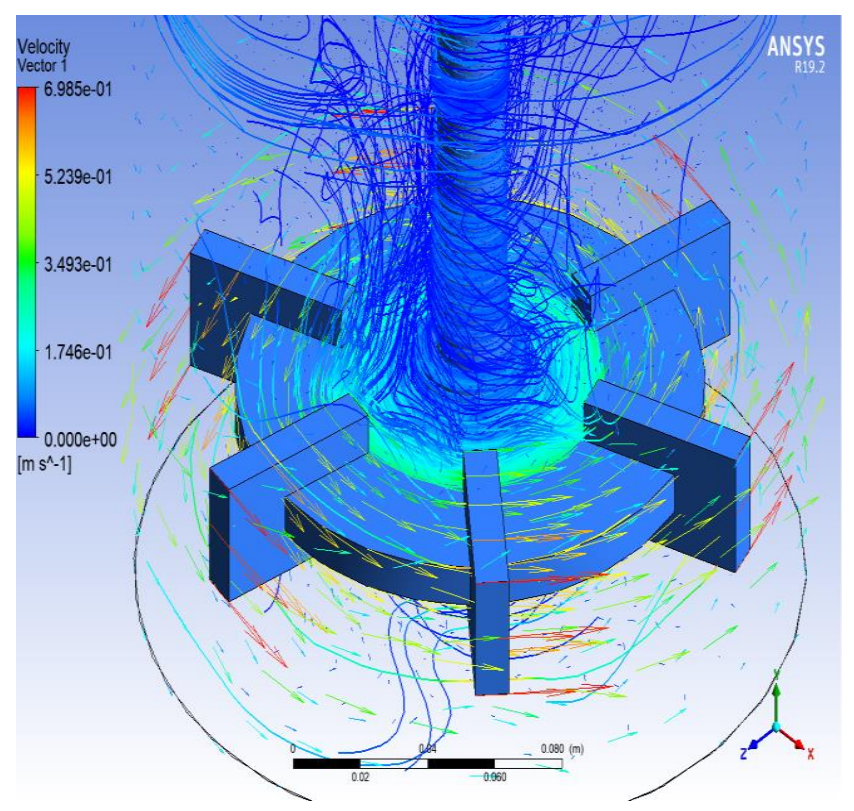

Figure 5. Insight view of the streamline 


\section{Turbulent Flow Behavior of Mixing Process Inside a Pharmaceutical Stirred Tank}

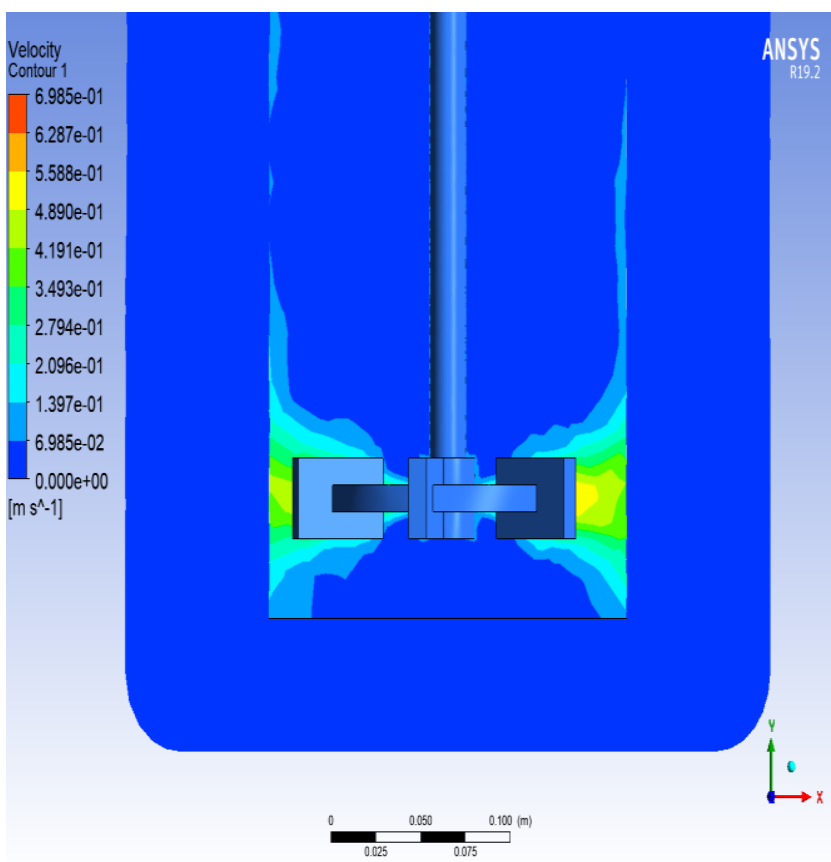

Figure6. Velocity contour of mixing process

The Figure 6 represent the velocity contour of the schematic mixing tank. The velocity which is developing due to the rotation of impeller induces high velocity at the region of blades that is imparted due to rotation. The Figure 7 represents the pressure contour of the schematic mixing tank. Due to the turbulence that is created due the swirl motion of the impeller the pressure is way developed by the blades that are imparted to rotation by the friction that is created between the blades and the water which is considered as the electrolyte medium. There are 2 cases that are analyzed, case1-The effect of velocity, case2-The effect of pressure that is been predicted with different case condition of varying rotational speed $4 \mathrm{rad} / \mathrm{sec}$, $8 \mathrm{rad} / \mathrm{sec}, 12 \mathrm{rad} / \mathrm{sec}$

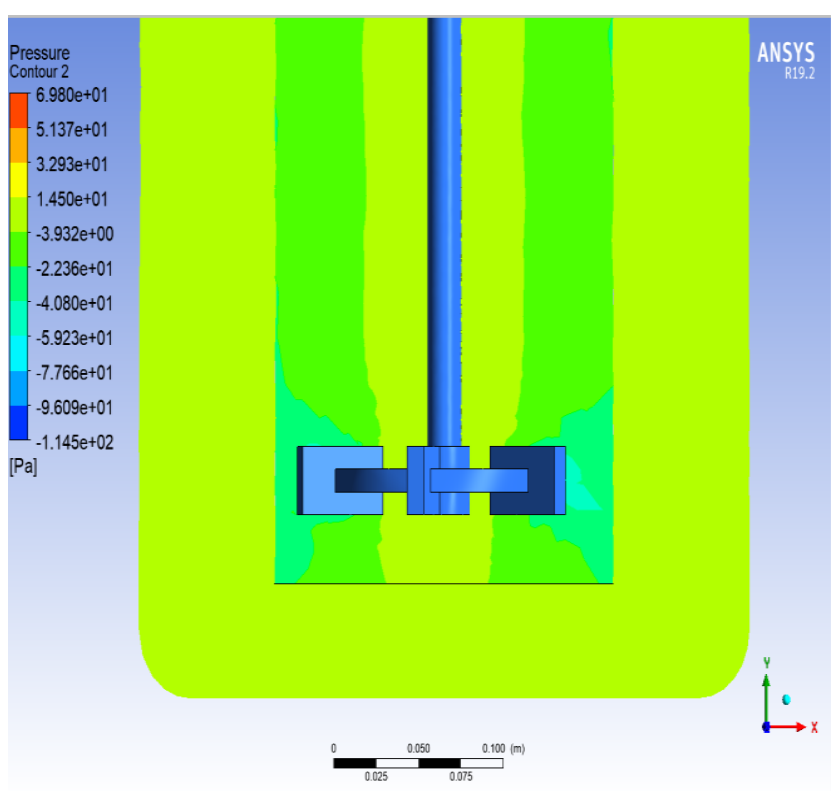

Figure 7. Pressure contours of mixing process

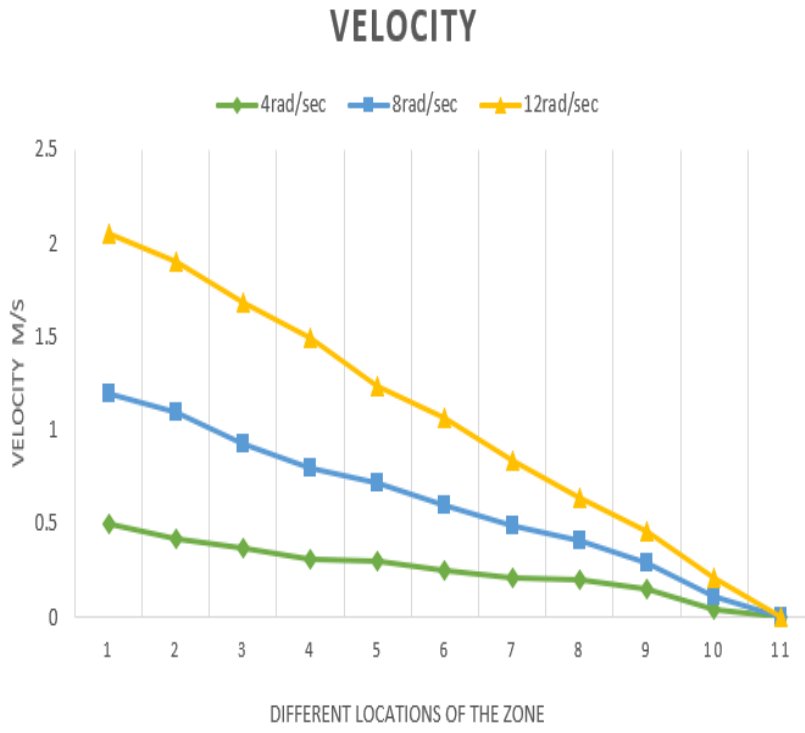

Figure 8. Graphical representation of velocity

The figure 5 represent the comparison of velocity pattern that is obtained for three different rotational speed conditions such as $4 \mathrm{rad} / \mathrm{sec}, 8 \mathrm{rad} / \mathrm{sec}, 12 \mathrm{rad} / \mathrm{sec}$. It is observed that the flow velocity of the mixing flow increases as the increase in speed of the impeller.

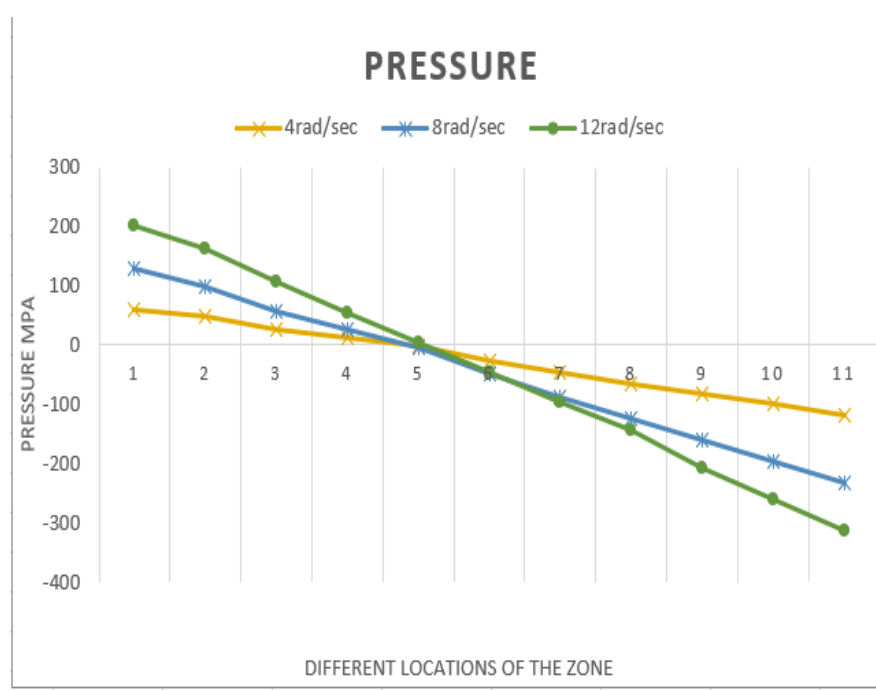

Figure 9. Graphical representation of pressure

The figure 9 represent the comparison of pressure pattern that is obtained for three different rotational speed conditions such as $4 \mathrm{rad} / \mathrm{sec}, 8 \mathrm{rad} / \mathrm{sec}, 12 \mathrm{rad} / \mathrm{sec}$. It is observed that the pressure of the mixing flow increases as the increase in speed of the impeller.

\section{CONCLUSION}

Hence the mixing dynamics can be clearly studied that is difficult to predict using CFD. The turbulent flow characteristics are understood by the information that is obtained. The flow characteristics of the impeller has been analyzed for different case conditions such as the impeller which is subjected to three varying rotational speed of $4 \mathrm{rad} / \mathrm{sec}, 8 \mathrm{rad} / \mathrm{sec}, 12 \mathrm{rad} / \mathrm{sec}$. It is proven that the flow physic varies for each rotational speed of the impeller. 
As the speed of the impeller increases the velocity and the pressure increases gradually, so this insist the impeller blade configuration significantly affects the performance of the mixing tank. Hence achieving the best impeller design will dominantly establish a good degree of homogeneity of mixing. This concludes that the using CFD it is easy to find out the best design of the mechanical mixing reactors that will guarantee the optimum results of the mixing output which also minimize the cost and time.

\section{REFERENCES}

1. M.Rahii, A.Parvareh, Experimental and CFD investigation on mixing by a jet in semi-industrial stirred tank, Chemical Engineering Journal, 2005, pp:85-92.

2. S. K. Naeeni, L. Pakzad, Droplet size distribution and mixing hydrodynamics in a liquid-liquid stirred tank by CFD modeling, International Journal of Multiphase Flow, 2019, pp:103-120.

3. R. N. Meroney, P. E. Colorado, CFD simulation of mechanical draft tube mixing in anaerobic digester tanks, Civil and Environmental Engineering, 2009, pp:1040-1050.

4. T. Hanada, K. Kuroda, K. Takahashi, CFD geometrical optimization to improve mixing performance of axial mixer, Chemical Engineering Science, 2016, pp:144-152.

5. A. R. Rammohan, A. Kemoun, M. H. Al-Dahhan, M. P. Dudukovic, A Lagrangian description of flows in stirred tanks via computer-automated radioactive particle tracking, 2001, pp:2629-2639.

6. M. Taghavi, R. Zadghaffari, J. Moghaddas, Y. Moghaddas, Experimental and CFD investigation of power consumption in a dua Rushton turbine stirred tank, Chemical Engineering Research and Design, 2011, pp:280-290.

7. L. Vicum, M. Mazzotti, Multi-scale modeling of mixing-precipitation process in a semibatch stirred tank, Chemical Engineering Science, 2007, pp:3513-3527.

8. R.Harish, Buoyancy driven turbulent plume induced by protruding heat source in vented enclosure,

International Journal of Mechanical Sciences,2018,pp:209-222.

9. R.Harish, Effect of heat source aspect ratio on turbulent thermal stratification in a naturally ventilated enclosure, Building and Environment, 2018,pp:473-486 .

10. R.Harish, K.Venkatasubbaiah, Non-Boussinesq approach for turbulent buoyant flows in enclosure with horizontal vent and forced inlet port, Applied Mathematical Modelling, 2016,pp:927-941.

11. R.Harish, K.Venkatasubbaiah, Numerical investigation of instability patterns and nonlinear buoyant exchange flow between enclosures by variable density approach, Computers \& Fluids, 2014,pp:276-287.

12. R.Harish, K.Venkatasubbaiah, Mathematical modeling and computation of fire induced turbulent flow in partial enclosures, Applied Mathematical Modelling,2013,pp:9732-9746.

13. R.Harish, K.Venkatasubbaiah, Numerical simulation of turbulent plume spread in ceiling vented enclosure, European Journal of Mechanics-B/Fluids,2013, pp:142-158.

\section{AUTHORS PROFILE}

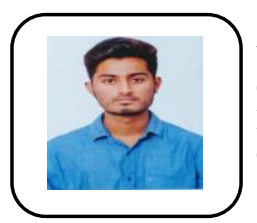

V. Sharan, is pursuing his M.Tech degree in $\mathrm{CAD} / \mathrm{CAM}$ at VIT Chennai Campus. His research Interest are in the field of Computational fluid dynamics and Computer aided design.

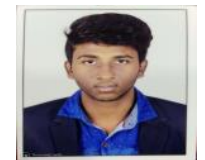

D. Bhuvaneshwar, is pursing his M.Tech degree in CAD/CAM at VIT Chennai Campus. His research Interest are in the field of Computational Fluid Dynamics and Manufacturing.

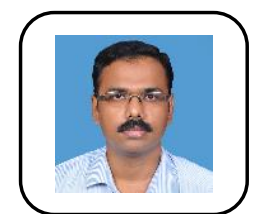

Dr. R. Harish, is working as an Assistant Professor in the school of Mechanical Engineering at VIT Chennai campus. His research interests are in the field of computational fluid dynamics, Heat Transfer and Turbulent flows. 